\title{
SALTA (ARGENTINA) COMO CIUDAD PATRIMONIAL Y COSMOPOLITA: LA DEFINICIÓN DE UN DESTINO TURÍSTICO "COMPETITIVO”
}

\author{
Claudia Alejandra Troncoso \\ Consejo Nacional de Investigaciones Científicas y Técnicas (CONICET) \\ Universidad de Buenos Aires. Argentina
}

\section{RESUMEN}

El presente trabajo aborda los procesos de transformación reciente de Salta (Argentina), ciudad que se ha definido en las últimas décadas como un importante destino turístico en el contexto nacional. En años recientes, desde el gobierno provincial (con colaboración de empresarios y expertos), se gestó un proyecto de renovación del área histórica orientado a estimular la llegada de turista que acentuó el carácter patrimonial de la ciudad pero también buscó definirla como una ciudad cosmopolita. Como parte de este proceso, el centro histórico se perfiló como un espacio de consumo turístico que también atrajo a ciertos sectores de la sociedad local.

Palabras clave: turismo- Salta- Argentina- patrimonio- cosmopolitismo- renovación urbana.

\section{Salta (Argentina) as a heritage and cosmopolitan city: the definition of a "competi-} tive" tourist destination

\section{ABSTRACT}

The paper deals with the recent processes that have transformed Salta into an important tourist destination in Argentina. In the last decades, provincial government (together with entrepreneurial actors and cultural and scientific experts) has launched an urban renewal program to revitalize the historic district and improve infrastructures to stimulate tourism.

Fecha de recepción: 2 de febrero de 2018

Fecha de aceptación: 18 septiembre de 2018

Consejo Nacional de Investigaciones Científicas y Técnicas (CONICET).

Universidad de Buenos Aires. Puan $4804^{\circ}$ piso. Instituto de Geografía (1406) CIUDAD DE BUENOS AIRES (Argentina). E-mail: claudia.a.troncoso@gmail.com 
This reinforced the heritage aspects of Salta but also sought to show it as a cosmopolitan city. As part of this process historic district has become a space of consumption for tourist and privileged local society.

Keywords: tourism- Argentina- Salta- heritage- cosmopolitism- urban renewal.

\section{INTRODUCCIÓN}

Algunas transformaciones de los espacios urbanos actuales han sido interpretadas como parte de procesos conocidos en la literatura especializada como "competencia entre ciudades". Esta competencia ha sido asociada a un interés en atraer inversiones y consumidores a las ciudades acompañado de la definición de áreas específicas vinculadas a distintos usos, especialmente al consumo de servicios y experiencias vinculadas al ocio y al turismo. Asimismo, esta estrategia de competencia con frecuencia es presentada por sus impulsores como garantía de integración en un nuevo mapa mundial donde las ciudades son protagonistas.

El presente trabajo aborda los procesos de transformación reciente de la ciudad de Salta (capital de la provincia del mismo nombre en el norte argentino) que se ha perfilado en las últimas décadas como un importante destino turístico en el contexto nacional. Algunas de las transformaciones que se produjeron en la ciudad pueden ser interpretadas formando parte de estas tendencias de competencia territorial que vienen orientando cambios en los espacios urbanos en las últimas décadas.

Como parte de este proceso de transformación, recientemente desde el gobierno provincial se apostó al turismo como actividad económica fuerte en la provincia. Para la ciudad de Salta, en particular, se ideó e implementó un proyecto de revitalización del área histórica (de fuerte impronta colonial) y mejora de infraestructuras para facilitar y estimular la llegada y permanencia de turista y para alentar las inversiones del sector privado ${ }^{1}$. Esto incluyó la definición de atractivos turísticos basados en su patrimonio resaltado por tareas de embellecimiento del centro histórico, pero también en una oferta cultural que incluyó la organización de eventos variados. Dos ideas inspiran este proceso: la que habla de Salta como ciudad histórica, y la idea de la ciudad como un centro de vanguardia, en conexión con el mundo. Todo esto conllevó la preparación y transformación del centro histórico tradicional de la ciudad como un espacio de consumo vinculado especialmente al turismo y también a ciertos sectores de la sociedad local.

La estructura de este artículo se compone por un primer apartado que desarrolla las perspectivas conceptuales que guían la interpretación de los procesos analizados, seguido de un segundo apartado con aclaraciones metodológicas. A continuación se caracterizan las principales líneas de la política turística local, para luego realizar un análisis de los procesos por los cuales se definió para Salta un perfil de ciudad patrimonial. Seguidamente se presentan aquellos aspectos que, desde la política pública, buscaron darle a la ciudad

1 Varias de estas iniciativas de gobierno se llevaron adelante mediante dos préstamos del BID desde 2003 (Préstamo BID N 1465/OC y BID N²835/OC-AR). 
un carácter cosmopolita para luego adentrarse en las formas de consumo que reúnen a turistas y residentes en el centro histórico de la ciudad. Hacia el final del texto se presentan reflexiones acerca de los resultados de la investigación a la luz de los procesos por los cuales se busca definir ciudades "competitivas" en la actualidad.

\section{ESTADO DEL ARTE Y PERSPECTIVAS DE INTERPRETACIÓN: LOS PRO- CESOS DE CREACIÓN DE ESPECIFICIDADES GEOGRÁFICAS EN LAS CIUDADES}

En términos generales, esta idea de una "competencia entre ciudades" asumida como garantía de integración en un nuevo mapa mundial (Sánchez, 2010) está caracterizada, entre otras cosas, por los intentos de rescatar o crear (y conjuntamente exhibir) particularidades geográficas variadas (Harvey, 1998). Ellas serán las que permitan definir a los centros urbanos como un producto y que habiliten a hablar a algunos autores de mercantilización de las ciudades (Sánchez, 2010). Buscar o generar una diferencia, en algunos casos, llevará a destacar diversos aspectos culturales de las ciudades que se plasmarán en procesos de transformación material y simbólica de algunas áreas específicas de los centros urbanos (con frecuencia sus centros históricos) para adecuarlas a estos fines.

Asimismo, se ha señalado que este proceso de transformación que comparten varios espacios urbanos se inscribe en una tendencia que busca transformar a las ciudades en espacios de consumo (Harvey, 1989; Britton, 1991; Zukin, 1995; Urry, 1995; Young, Diep y Drabble, 2006; Jayne, 2006). A diferencia de lo que acontecía en otros momentos históricos donde las ciudades se definían por su condición de lugares de localización de actividades productivas, en las últimas décadas se observa una tendencia a la consolidación del sector terciario y la creación de diferentes opciones orientadas al consumo, en gran medida articuladas alrededor del ocio, la cultura y el turismo (Zukin, 1998).

Más allá de sus aspectos culturales o históricos, algunas ciudades se han lanzado a esta competencia mostrándose como lugares cosmopolitas. La noción de cosmopolitismo está asociada tradicionalmente, por un lado, con la idea de una ciudadanía que se asume global en detrimento de ciertas lealtades hacia la nación o lo vernáculo (Young, Diep y Drabble, 2006). Así, hoy en día, en un contexto de intensa movilidad, por ejemplo, se habla de una "identidad cosmopolita" (Hiernaux, 2011) detentada por aquellos que comparten referentes identitarios que no remiten a la nación. Por otro lado, la noción de cosmopolitismo tiene en su centro la idea de una disposición de apertura hacia lo diferente (culturas, lugares, experiencias) y la aceptación de la diversidad (Urry, 2000). Distintos actores (elites globales, artistas, intelectuales, migrantes) han sido presentados y analizados como cosmopolitas (entre ellos los turistas) quienes, entre otras cosas, se dan a la búsqueda de lo diferente, lo novedoso, las experiencias desconocidas.

Pero también la idea de cosmopolitismo se ha asociado con determinados ámbitos geográficos en particular. Y aquí las ciudades tienen un lugar preeminente: ellas han sido históricamente centros de intercambio y encuentro de personas, culturas, ideas, mercancías, etc. También lugares donde se gestaban movimientos e instituciones sociales y culturales nuevas (Featherstone, 2002), de avanzada, admirados e imitados en otros contextos. Precisamente esta idea será retomada para proponer estos nuevos modelos de ciudad 
que se han generalizado en las últimas décadas: la creación de una ciudad que ofrezca o favorezca situaciones de encuentro y de involucramiento con lo diferente (o que aspire a hacerlo) (Young, Diep y Drabble, 2006). En este sentido es que se habla de Salta como ciudad cosmopolita en este texto.

En general estos procesos han sido estudiados para el caso de las metrópolis o grandes ciudades industriales; en estos contextos las tareas de renovación urbana orientadas a la definición de nuevos espacios de consumo se interpretaron como una estrategia para superar la desindustrialización que experimentaron muchos centros urbanos a partir de las últimas décadas del siglo XX y para revertir la imagen negativa que muchos de ellos tenían (Young, Diep y Drabble, 2006). Sin embargo, algunos aspectos de estos procesos son compartidos por centros urbanos sin pasado industrial. Este es el caso de la ciudad de Salta.

Asimismo, estos procesos se han analizado reconociendo distintas dimensiones. Ward (2005) propone tres aspectos en estos procesos de "reinvención de las ciudades", como los llama. El primero de ellos es la dimensión simbólica que se expresa en la definición de una imagen de la ciudad creada a través del marketing urbano. Esto permite darle forma a esta imagen mediante un proceso de selección de rasgos de la ciudad que, aplicando paralelismos con las estrategias del mundo empresarial, se estiman acordes con lo demandado por el consumidor (residente, turista) o los empresarios inversionistas (Sánchez, 2010). El proceso de selección de rasgos de la ciudad orienta otra de las dimensiones, la que se vincula con los aspectos materiales de la ciudad, es decir, las transformaciones en el espacio edificado en consonancia con esa imagen. Procesos de renovación de centros históricos y waterfronts con la conservación, reconstrucción y refuncionalización de edificios, el cuidado de fachadas y la apariencia general del espacio público unido a la creación de una normativa específica que defina el rumbo de estas transformaciones forman parte de esto. Una última dimensión remite a las nuevas formas de pensar e implementar la gestión de las ciudades. Apoyadas fuertemente en los valores del neoliberalismo y la globalización (Sánchez, 2010) se destacan por: la idea de hacer partícipes a las ciudades de esta competencia para incluirlas en el escenario mundial; la planificación de tipo especulativa marcada por la preocupación muy presente en el mundo empresarial por alcanzar resultados -el éxito-; y la asociación público-privado marcada por la fuerte injerencia del sector privado en la gestión pública (Harvey, 1989; Vainer, 2000; Sánchez, 2001).

Las experiencias concretas inspiradas por estas tendencias e ideas pronto se presentaron como exitosas y devinieron modelos para imitar en otros contextos, en una propuesta alentada por un discurso prescriptivo emanado de la academia y los organismos internacionales (Sánchez, 2010). Estas experiencias, de alguna manera, se repitieron como receta necesaria para una integración "exitosa" en el mundo actual (Sánchez, 2010; Young, Diep y Drabble, 2006). Los casos de Baltimore (Harvey, 1998), Nueva York (Zukin, 1995; Boyer, 2004) y Barcelona (Sánchez, 2010) figuran entre los más elogiados y emulados.

El patrimonio ha sido uno de los elementos a los que se ha echado mano para reforzar aspectos distintivos de los lugares (Harvey, 2002). Algunos antecedentes sobre el caso de Salta han dado cuenta de cómo recientemente se ha redefinido como una ciudad patrimonial (Troncoso, 2011; Troncoso, 2013a; Troncoso, 2013b). Pero también otros 
aspectos están siendo puestos en juego en este proceso de transformarla en un destino turístico relevante a nivel nacional. Ciertas ideas y acciones, que son parte de los procesos de redefinición de la ciudad como destino turístico, se orientan a hacer de Salta no solo una ciudad patrimonial sino también una ciudad moderna, cosmopolita, vanguardista, de primer orden en el contexto nacional. Una ciudad que responda al interés por el pasado y por el presente que ha caracterizado al turismo urbano en los últimos dos siglos (Duhamel, 2005).

\section{ASPECTOS METODOLÓGICOS}

El trabajo tiene como objetivo poner la atención en este proceso de transformación orientado a definir a Salta como un lugar patrimonial, cultural, pero también moderno y cosmopolita para un público usuario/consumidor que incluye turistas pero también ciertos sectores de la sociedad local. Para ello se analizan aspectos interrelacionados: por un lado, las formas de definir una imagen para Salta a partir de estas ideas y, por otro, las transformaciones materiales y sociales que la acompañaron. Esto se desarrolla teniendo en cuenta el accionar de diferentes actores: el poder político provincial y municipal (en especial aquellos que le dieron forma a la política turística y patrimonial desplegada en las últimas décadas), el empresariado turístico y el saber experto. Asimismo, se presentan los usos vinculados centralmente con el turismo y el ocio a los cuales se orientó el centro histórico en los últimos años. En definitiva, el trabajo busca, a través del análisis de un caso particular, continuar indagando en el papel que tiene el turismo en los procesos de transformación urbana vinculado a las tendencias identificadas como competencia territorial y cuáles son las implicancias de estos procesos. En este sentido, el trabajo se inspira en preguntas más generales, entre ellas: ¿cómo son rescatadas, acondicionadas, inventadas (creadas) ciertas características del espacio (urbano) que resultan o se suponen interesantes para el turismo actual?, ¿cómo estas particularidades de los lugares confluyen con nuevas formas que toman la promoción y diseño de nuevas propuestas turísticas y cómo también convergen nuevos intereses por parte de los turistas?, ¿quiénes participan de estos procesos de transformación de las ciudades?, ¿cuáles son las estrategias para hacerlo?, ¿qué discursos justifican este accionar que le otorga un lugar privilegiado a la ciudad disfrutable en términos turísticos y de ocio (frente a otras dimensiones de la vida en los centros urbanos)?, ¿qué formas de gestión de la ciudad trae de la mano?

Para la realización de este trabajo se analizaron documentos oficiales elaborados por el gobierno provincial (planes de desarrollo turístico e informes de gestión, y además, normativas vinculadas a la gestión patrimonial) así como piezas de promoción turística confeccionados por distintos niveles de gobierno, y por el sector privado (folletería, publicaciones especiales oficiales, spots publicitarios, guías turísticas, páginas web). También se consultaron noticias periodísticas referidas a la política turística y patrimonial y las transformaciones de la ciudad. Además, se utilizaron fuentes primarias que incluyen entrevistas realizadas entre el 2010 y el 2017 a actores vinculados con la implementación de esta política desde las dependencias oficiales del gobierno municipal y provincial, miembros de la Cámara de Turismo provincial y titulares de locales comerciales del centro histórico. 


\section{SALTA: COMPETENCIA Y "ASCENSO" DE LA MANO DEL TURISMO}

La ciudad de Salta (ver localización en figura 1) tiene una población de 535.503 habitantes según el Censo Nacional de Población Hogares y Vivienda de 2010. Esto representa casi la mitad del total de la población de la provincia de la cual es capital. Este núcleo urbano fue fundado en 1582 durante el dominio español en América con el fin de reforzar la presencia del Virreinato del Perú en esa área (Gobernación del Tucumán) y asegurar el comercio entre la ciudad de Córdoba (al sur de Salta, actualmente también Argentina) y el área del Alto Perú (al norte, actualmente Bolivia). La ciudad fue posteriormente sede de la Intendencia de Salta del Tucumán (jurisdicción del Virreinato del Río de la Plata creado en 1776). En ese entonces se consolidó como un importante núcleo que vinculaba la ciudad de Buenos Aires con el centro minero de Potosí (Mata de López, 1998). Este momento histórico colonial, cuando Salta cobra relevancia y auge regional, marca fuertemente la identidad salteña. Asimismo, este pasado colonial ha sido retomado por el turismo al momento de seleccionar rasgos distintivos del lugar, como se verá más adelante. En la historia más reciente este centro urbano prácticamente no concentró actividades productivas sino que se especializó en el sector servicios (fundamentalmente comercio y administración pública). Su condición de destino turístico nacional fue consolidándose a lo largo del siglo XX conforme el turismo se instalaba como práctica de ocio a la que accedía de manera creciente la sociedad argentina. En general, la visita a la ciudad de Salta se encuentra incluida en un conjunto de destinos del noroeste del país que se visitan en el mismo viaje como los Valles Calchaquíes, la Quebrada de Humahuaca, la Puna e incluso otros de Chile, Bolivia y Perú. El pasado prehispánico y colonial, las batallas de la lucha por la independencia, las costumbres asociadas a la vida campesina andina, diferentes manifestaciones culturales y religiosas, las ruinas del Sistema Vial Andino (Qhapaq Nan), las actividades productivas agrarias tradicionales (incluida la vitivinicultura) constituyen algunos de los aspectos de esta zona de la Argentina que se valoran como atractivos turísticos. La ciudad de Salta, en particular, se perfiló como un importante centro de llegada y estadía de turistas nacionales y, de manera creciente, internacionales (los turistas nacionales representan más del 80\% del total de turistas). En ella se concentra más de la mitad de las plazas hoteleras de la provincia y buena parte de los servicios de excursiones hacia los otros destinos regionales (el 86\% de las agencias de viaje que operan en la provincia tienen sede en la ciudad de Salta) (Ministerio de Cultura y Turismo, 2017). Asimismo, en la ciudad se realizan paseos que incluyen de manera central la visita a diferentes monumentos históricos. Recientemente el crecimiento que el turismo experimentó en la ciudad (siguiendo tendencias a nivel nacional y provincial) ${ }^{2}$ fue estimulado por una política turística que procuró la dinamización económica y laboral de la mano de esta actividad. Y esto resultó una idea atractiva en una ciudad que en los últimos años ha presentado niveles de desocupación elevados ${ }^{3}$.

2 Según las estimaciones oficiales la cantidad de arribos turísticos a la provincia de Salta pasó de 285.000 en 1995 a 1.673 .734 en 2016. En la ciudad de Salta, la cantidad de plazas hoteleras pasó de 5.796 en 2004 a 11.743 en 2016.

3 La Encuesta Permanente de Hogares realizada por el Instituto Nacional de Estadísticas y Censos señala que para el tercer trimestre del 2017 la tasa de desocupación para la ciudad de Salta era de 8,5\% (el mismo valor para los 31 aglomerados del país en los que se realiza la encuesta es de 8,3\%). 


\section{Figura 1 \\ LOCALIZACIÓN DE LA CIUDAD DE SALTA EN LA ARGENTINA}

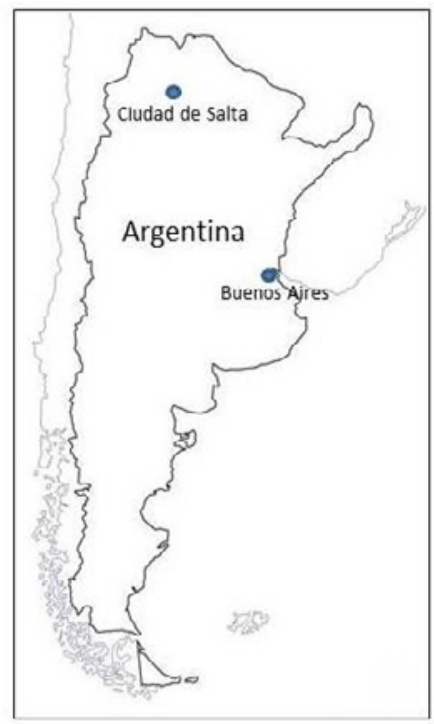

Las formas que tomaron las iniciativas en materia de política turística (y también patrimonial) de la provincia de Salta hablan de una clara apropiación de este discurso vigente que desde varios ámbitos (fundamentalmente desde el académico y el de la gestión) indica la necesidad de hacer de las ciudades lugares competitivos. En este caso particular, el status de ciudad competitiva sería procurado de la mano del turismo, una actividad con cierta tradición en toda la provincia. En efecto, como ya fue indicado en otros trabajos, la idea de hacer de Salta un destino turístico de relevancia nacional e internacional aparece como un objetivo de la política turística provincial que se desarrolló en las últimas décadas (Troncoso, 2011; Troncoso, 2013a; Troncoso, 2013b). Los dos pilares de este proceso fueron una política provincial de estímulo al turismo en un contexto en el que comenzó a incrementarse la cantidad de turistas en la Argentina y la revitalización del centro histórico de la ciudad que también constituyó una iniciativa del gobierno provincial. Impuso al turismo y transformación urbana fueron la punta de lanza de un proceso que desde comienzos de la década de 2000 tiene como protagonistas tanto al sector público como al privado.

Como parte de este proceso, el gobierno provincial encaró una serie de acciones para favorecer la inversión privada a través de exenciones impositivas y créditos fiscales que permitió ampliar la cantidad de plazas disponibles (BID, 2003). La capital provincial concentra casi el $60 \%$ de las plazas de alojamiento de la provincia por lo que este estímulo tuvo un impacto importante a nivel local. A esto se le agrega el otorgamiento de excepciones para la construcción en altura en el centro histórico que permitieron la inauguración, a mediados de la década de 2000, de los dos hoteles cinco estrellas de la ciudad. Además, 
se realizaron obras de infraestructura y mejoras en los servicios (como la construcción de un centro de convenciones, la modernización de la terminal de ómnibus, el mejoramiento en los accesos a la ciudad y el aumento de vuelos y destinos desde y hacia el aeropuerto local). Esto también se presentó como un aspecto excepcional en el contexto regional mostrando la intensidad de las conexiones que establece Salta con el mundo ${ }^{4}$.

Los intentos por hacer de la ciudad de Salta un lugar destacado frente a otros se expresan en varios puntos de este proceso encarado por el poder político. Tanto se trate de la ciudad o de la provincia entera, aparece claramente la intención de hacer "escalar" a Salta en un ranking de destinos a nivel nacional e incluso internacional a fuerza de destacar su condición de centro indiscutido de turismo y cultura del noroeste. De esta manera lo expresan los funcionarios del gobierno provincial señalando, incluso, el desplazamiento de la ciudad de San Miguel de Tucumán como referente cultural histórico del noroeste argentino:

\begin{abstract}
"Quiero agradecer el esfuerzo de todos por este año realmente maravilloso que hemos tenido en el campo del turismo y la cultura consolidando a Salta como centro del norte argentino en ambos aspectos: en lo cultural y lo turístico. Ha habido eventos como nunca en la provincia de Salta en el aspecto cultural pero bueno los desafíos continúan no hay que dormirse en los laureles. Salta no tiene techo" (Discurso del Ministro de Cultura y Turismo con motivo de la presentación del Anuario 2010 que realizó esta dependencia en diciembre de 2010).

"Salta siempre fue una provincia de mucho crecimiento a nivel turístico [...] Salta siempre fue una de las cabeza del NOA y la cabeza cultural era Tucumán. Pero bueno, hace unos diez años empieza a perder ese eje y toda la actividad cultural se viene y se empieza a desarrollar acá, en la provincia de Salta, en la ciudad de Salta, concretamente" (entrevista personal con el Secretario de Turismo de la ciudad de Salta, diciembre de 2010).
\end{abstract}

Esta competencia frente a otros destinos también se expresa en términos de una lucha por lograr que el turista no sea captado por otros:

\begin{abstract}
"Nuestro principal mercado es Buenos Aires, desde Buenos Aires a Salta antes había 3, 4 destinos que haciendo promoción les ganabas. Ahora vos vas a Buenos Aires y tenés promoción de 50 destinos en el país. Desde Bs As hay muchas ofertas hasta llegar a Salta, que te las pueden ir robando, entonces tenemos que reapuntar nuestra promoción, nuestra estrategia de desarrollo con el objetivo de seguir consolidándonos como uno de los principales destinos en Argentina" (Entrevista Subsecretaría de Promoción y Desarrollo, Ministerio de Cultura y Turismo de Salta, 2010).
\end{abstract}

Pero las aspiraciones para Salta no se limitan al ámbito doméstico sino que también apuntan a jugar en el escenario mundial, tal como lo señala quien fuera intendente de la ciudad entre 2003 y 2015 al afirmar que "Salta tiene que estar entre las ciudades más importantes y conocidas del mundo" (El Tribuno, 2012).

El interés por participar de esta competencia de ciudades apostando al turismo no queda en simples declaraciones de funcionarios; también se hace evidente en los dos

4 Por ejemplo, la promoción turística oficial hace hincapié en el aeropuerto de la ciudad como el "quinto aeropuerto con mayor movimiento del país" (ver Ministerio de Cultura y Turismo, 2013a). 
últimos planes de desarrollo turístico implementados para la provincia donde se propone posicionar y mantener a la ciudad en este lugar de privilegio (Ministerio de Cultura y Turismo de Salta, 2007 y 2012a).

Por supuesto, la idea de que el turismo generará desarrollo o mejorará las condiciones de vida se hace presente como elemento legitimador de la política diseñada ${ }^{5}$. En relación con esto la sociedad salteña es interpelada con un pedido: el de colaborar con el turismo para impulsar su crecimiento (en vistas de los beneficios que genera). Pero también con un reconocimiento: el de ser artífice del éxito de la empresa justamente por haber colaborado con la tarea. Aquí, como en otros casos, se recurre a estrategias que buscan adhesión a partir de referencias a lo afectivo, a la identidad provincial y al proyecto conjunto con beneficios para todos. En este sentido, en estos intentos por comprometer en el proyecto turístico a la sociedad local se ha invocado algo que se reconoce con orgullo como un rasgo identitario a nivel provincial: la idea de la hospitalidad salteña ${ }^{6}$.

Todo esto se apoya en la exhibición de las estadísticas turísticas (tan caras a la gestión sectorial) que dan cuenta de crecimientos cuantitativos de turistas, pernoctes y gastos realizados por los visitantes. Ellas son exhibidas como "pruebas" de un camino exitoso que tomó la política sectorial, celebradas también por el sector empresarial7

En este proceso de transformaciones vinculadas con el turismo se evidencia uno de los aspectos de las formas de gestión actual de las ciudades: la existencia de un proyecto común entre el sector público y el privado. Esta cuestión queda expresada en las frases recurrentes (de funcionarios y empresarios) que aseguran que el éxito del turismo en la provincia se debe a un "trabajo mancomunado" o a la "sinergia" entre el sector público y privado; de hecho, el Ministerio provincial cuenta con un Consejo Asesor del que participa la Cámara de Turismo provincial ${ }^{8}$.

De la mano del interés por hacer de Salta un destino destacado también hay una preocupación por recibir consumidores/turistas específicos. La apuesta al turista de alto poder adquisitivo es central en la política turística que se está diseñando. Así lo afirmaba el ministro provincial en 2011 cuando manifestó que la estrategia del ministerio a su cargo buscaba "capturar al nivel socioeconómico que más gasta", agregando que "por eso desarrollamos muchas ofertas con hoteles boutique, de 4 o 5 estrellas. La relación con las

5 El gobernador provincial, por ejemplo, expresa que "Hay que seguir en esa misma línea, porque sabemos lo que significa para Salta la actividad turística como motor de desarrollo, como generadora de empleo y como herramienta para brindar mayores posibilidades de inclusión" (Ámbito Financiero, 2016). Asimismo, desde el gobierno provincial también se afirma que "El impacto económico que dejaron los turistas [en enero y febrero de 2014] ascendió a $\$ 570$ millones que se distribuyeron de forma directa e indirecta en todos los estratos sociales" (Ministerio de Cultura y Turismo de Salta, 2015). Véase, además, el énfasis que se coloca en la idea de que el turismo en Salta repercute en un incremento de opciones en el mercado laboral tanto en informes de gestión (Ministerio de Cultura y Turismo, 2013a) como en spots publicitarios (Ministerio de Cultura y Turismo, 2010) y cómo se insiste en la clásica idea de "derrame" asociada a la actividad (Ministerio de Cultura y Turismo de Salta, 2014).

6 Véase, nuevamente, el spot publicitario de 2010 (Ministerio de Cultura y Turismo, 2010).

7 Además de los ejemplos citados anteriormente, véanse, por ejemplo, las declaraciones de representantes de la gestión provincial y municipal, y de empresarios en las siguientes noticias: Pulso turístico (2014), La Gaceta (2015) y El Tribuno, (2015).

8 Las referencias a este trabajo en común entre ambos sectores han sido señaladas en sucesivas entrevistas personales realizadas en la Secretaría de Turismo de la Municipalidad, la Subsecretaría de Promoción y Desarrollo del Ministerio provincial de Cultura y Turismo y la Cámara de Turismo de la provincia desde 2010 a 2016. 
bodegas y los vinos de altura ${ }^{9}$ también es una forma de vincularnos al segmento de alta gama que también empieza a percibir que si Salta es capaz de hacer los vinos de calidad también puede servir turismo de calidad" (Informate Salta, 2011) ${ }^{10}$.

En definitiva, se busca que Salta siga las tendencias de transformación urbana internacional, buscando sumarla al grupo de las principales ciudades de Argentina. Parecería que se procura incluir a Salta en un ranking, a la manera de los que se elaboran a nivel internacional para indicar cuáles son las ciudades que han "ganado" esta competencia urbana global (Sánchez, 2010). Pero la presentación de Salta como un caso "exitoso" en lo turístico no debe entenderse como un accionar limitado a ese rubro. En gran medida, puede interpretarse como parte de un proyecto político que intenta posicionar una imagen positiva de la provincia (y por extensión de los responsables de su gestión) en el contexto nacional. Esto último cobra más sentido al considerar las aspiraciones presidenciales manifiestas del gobernador provincial y su rol en el escenario político nacional en los últimos años.

\section{SALTA COMO CIUDAD PATRIMONIAL: EL PASADO COMO ATRACTIVO}

Como se mencionara, los aspectos históricos de Salta se encuentran entre los atractivos más destacados de la ciudad. Esto se apoya en un conjunto de edificaciones del período colonial y otras más recientes (siglo XIX y XX) localizadas en su centro histórico. En gran medida, estos referentes arquitectónicos hablan del rol de la ciudad como importante centro político, económico y demográfico durante el dominio colonial español, así como también de referentes de la sociedad local que incluye héroes de la lucha por la independencia $^{11}$ y familias de renombre que han conformado la elite local.

La apuesta al turismo a comienzos de la década de 2000 tuvo foco en este centro histórico de la ciudad de Salta que fue objeto del Programa de Recuperación del Casco Histórico, el cual incluyó acciones como restauración, pintura e iluminación de edificios emblemáticos (algunos de ellos con distinciones patrimoniales previas) ${ }^{12}$, y la instalación de un equipamiento urbano de tipo histórico que procuró realzar el carácter patrimonial del área (incluyó las farolas adosadas a la pared que luce la ciudad en muchas de sus esquinas

9 Esta actividad se desarrolla en los Valles Calchaquíes, centro turístico tradicional cercano a la ciudad de Salta y especializado en la producción de vinos de altura, en especial del torrontés.

10 Otras declaraciones de funcionarios de esta dependencia van en el mismo sentido: "Nuestro gran objetivo ahora no es empezar a trabajar por mayor cantidad de turistas sino por menor cantidad de turistas, pero con mayores ingresos. Sabemos que el turista que viene con más ingresos no solo gasta más, también genera más actividades. Ese era el objetivo en este periodo" (Entrevista Subsecretaría de Promoción y Desarrollo, Ministerio de Cultura y Turismo de Salta, 2010). Asimismo, la incorporación de productos de alta gama aparece como uno de los objetivos del plan de desarrollo turístico vigente: "la estrategia radica en diseñar una promoción a medida que consolide la imagen de Salta como un destino de calidad, diversifique su oferta incorporando nuevos productos, entre ellos los de alta gama, y profundice la presencia de productos especializados y de nicho en las distintas acciones promocionales que se desarrollen" (Ministerio de Cultura y Turismo, 2012a: 103-104).

11 Aquí se destaca la figura de Martín Miguel de Güemes, un militar salteño que participó en la guerra por la independencia argentina comandando milicias compuestas en su mayoría por gauchos. Güemes y los gauchos salteños forman parte central de los referentes identitarios de la sociedad salteña.

12 Como la Catedral, el Cabildo Histórico, el Convento de San Bernardo, el edificio de la Jefatura de Policía, los museos de Arte Contemporáneo (MAC) y Arqueología de Alta Montaña (MAAM), el Palacio Legislativo (muchos de ellos localizados en los alrededores de la plaza principal 9 de Julio). 
y una nueva cartelería para la señalización de calles, ambas de inspiración colonial) (ver figura 2). Así, la versión patrimonial se apoya (a la vez que colabora) en la definición de lo que se ha consolidado como la versión hegemónica de la identidad salteña (Álvarez Leguizamón y Villagrán, 2010) que reconoce el período colonial como momento fundacional de la sociedad local y recupera los aspectos de Salta como ciudad patricia, noble y próspera.

\section{Figura 2 \\ CATEDRAL DE LA CIUDAD DE SALTA DESPUÉS DE LAS TAREAS DE PIN- TURA E ILUMINACIÓN}

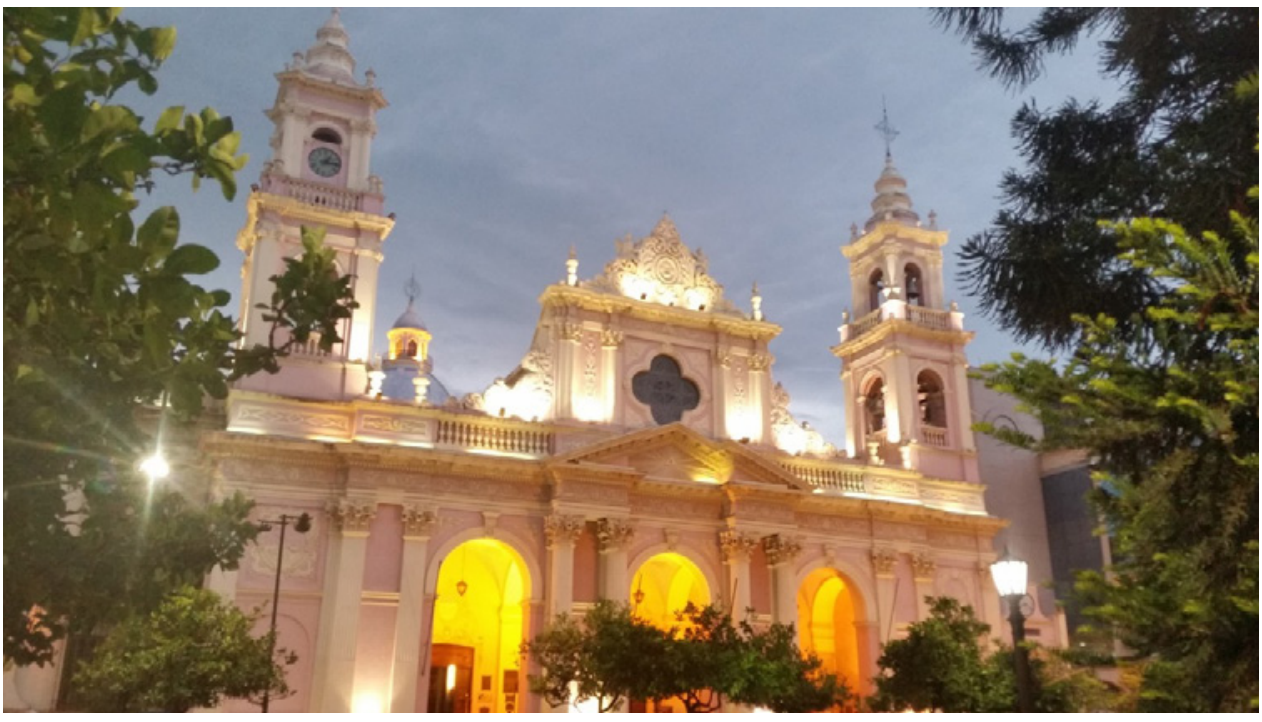

Estas acciones, que apuntaron a recuperar el valor simbólico del centro (Herzer, 2008) que ya no era frecuentado por los sectores más privilegiados de la sociedad local, se complementan con una serie de normativas de protección que incluye la delimitación del área patrimonial ${ }^{13}$, y en especial con la creación en 2011 del Plan Regulador Área Centro Ciudad de Salta (PRAC) que contiene un conjunto de disposiciones que fijan criterios acerca de la apariencia y usos del centro histórico (Ministerio de Finanzas y Obras Públicas de Salta, 2011).

Otras ciudades darán la pauta de cómo encarar estas transformaciones y el caso de Salta se orientará por experiencias previas o modelos a seguir. En el PRAC la ciudad de Barcelona aparece como gran referente, junto con otras (Santiago de Chile, Lima, Rosario, etc.). En particular, la consideración de Barcelona como modelo de planificación urbana se plasma en actividades de asistencia técnica que expertos catalanes realizaron para la CoPAUPS -Comisión de Preservación del Patrimonio Arquitectónico y Urbanístico de la

13 El Área Centro de la Ciudad de Salta es declarada por Decreto Provincial N²735 de 2009 "Bien de Interés Arquitectónico y Urbanístico de la Provincia de Salta”. Mediante este decreto se delimita el área de la ciudad que tendrá un nuevo estatus y quedará bajo una gestión especial vinculada a su condición patrimonial. 
Provincia de Salta- al inicio de la puesta en vigencia del PRAC en 2011'4. Este know how exportado desde un contexto "exitoso" 15 funciona a modo de legitimación (Sánchez, 2010) del proyecto salteño de renovación urbana.

El énfasis que la política turística colocó en el patrimonio de la capital salteña se refuerza de la mano de una intensa tarea de promoción turística. Ella se manifestó en la creación y difusión de campañas gráficas y spot publicitarios, la presencia en ferias y eventos y la elaboración y entrega de materiales turísticos impresos a turistas y agencias de viaje. Mediante estas estrategias y a través de imágenes y descripciones se hace hincapié en un imaginario patrimonial (Hiernaux, 2006) basado en la idea de ciudad colonial, noble, patricia, cuna de la tradición y celosa de su pasado, acompañada de referencias a la figura del gaucho (especialmente cuando se lo vincula a Güemes) y otros aspectos como su condición de sede del folklore provincial y de eventos vinculados con distintas manifestaciones de la religiosidad católica (Troncoso, 2011; Troncoso, 2013b).

Estos aspectos de la ciudad resaltados a través de la política turística y patrimonial son los que están presentes en los recorridos que realizan los turistas en la ciudad de manera individual o mediante la contratación de servicios de city tour. Ellos enlazan la visita a edificaciones eclesiásticas, civiles y domésticas localizadas en el centro histórico junto con monumentos a héroes y eventos considerados de relevancia local o nacional.

Ciertos aspectos del pasado salteño, reforzados institucionalmente a través de un tratamiento y de distinciones patrimoniales, son elementos centrales de la creación de estas especificidades geográficas que vuelven distintivos los lugares de los cuales se espera que compitan en el escenario mundial. El patrimonio histórico, sin embargo, no será el único elemento al que se eche mano para distinguir a la ciudad.

\section{ACOMPAÑANDO EL PATRIMONIO: LA DEFINICIÓN DE LA CIUDAD DE SALTA COMO UN DESTINO CULTURAL, VANGUARDISTA Y COSMO- POLITA}

Si bien la idea de ciudad competitiva tiene en su centro una versión del pasado salteño, también se incluyen ciertas condiciones que la muestran como una ciudad moderna, en sintonía con la idea de "ciudad cosmopolita" presente en las nuevas tendencias de planificación y gestión de ciudades. Los intentos por definir a la ciudad como un lugar que posee este perfil se apoyó en la promoción de algunos atractivos culturales y de entretenimiento, así como servicios "de jerarquía” que no necesariamente forman parte de los aspectos habitualmente destacados para la ciudad centrados en su patrimonio histórico. Estas ideas fuertemente difundidas se apoyan en (y a su vez respaldan) un conjunto de acciones concretas de intervención en el espacio urbano que forman parte de la política pública turística y patrimonial y del accionar del sector privado.

14 Esto se efectivizó en el marco de un convenio de capacitación técnica entre la cancillería argentina y el gobierno catalán y como parte de ello los expertos brindaron cursos de capacitación a los especialistas salteños.

15 En las noticias oficiales y aquellas reproducidas por periódicos locales de los expertos visitantes solo se dice que son catalanes (no se dan especificaciones acerca de su experiencia profesional) como si su origen bastara para justificar el recurrir a ellos como asesores en materia de planificación urbana (ver, por ejemplo, cómo se comunicaban sus actividades en la página del Gobierno de la provincia (Ministerio de Cultura y Turismo, 2011). 
Así, uno de los aspectos que va a ser clave en el retrato de una ciudad cosmopolita para el turista exigente es la forma en que se presentan los propios emprendimientos hoteleros de la ciudad. La misma oferta de servicios aparece como un atractivo turístico que avala la idea de una ciudad destacada. Aquí el fuerte serán los dos hoteles 5 estrellas que tiene la ciudad, los primeros en ser construidos en todo el noroeste del país. Los materiales oficiales de promoción no dejan de mencionar estos exponentes de la hotelería local a la que se le suman otros emprendimientos que siguen las nuevas tendencias en alojamiento que apuntan a un turista selecto como son los hoteles boutique. Los mismos emprendimientos hoteleros hacen hincapié en su carácter vanguardista que se muestra en armonía con aspectos más idiosincráticos y tradicionales asignados a la sociedad local ${ }^{16}$ (ver figura 3). De esta manera, el turista de estos tiempos, conocedor de los detalles de la cultura local pero también exigente de estándares presentes en otros lugares del mundo, parecería encontrar en Salta elementos que responden a sus necesidades.

\section{Figura 3}

\section{FOLLETO PROMOCIONAL DE UN HOTEL LOCALIZADO EN EL CENTRO HISTÓRICO (2012)}

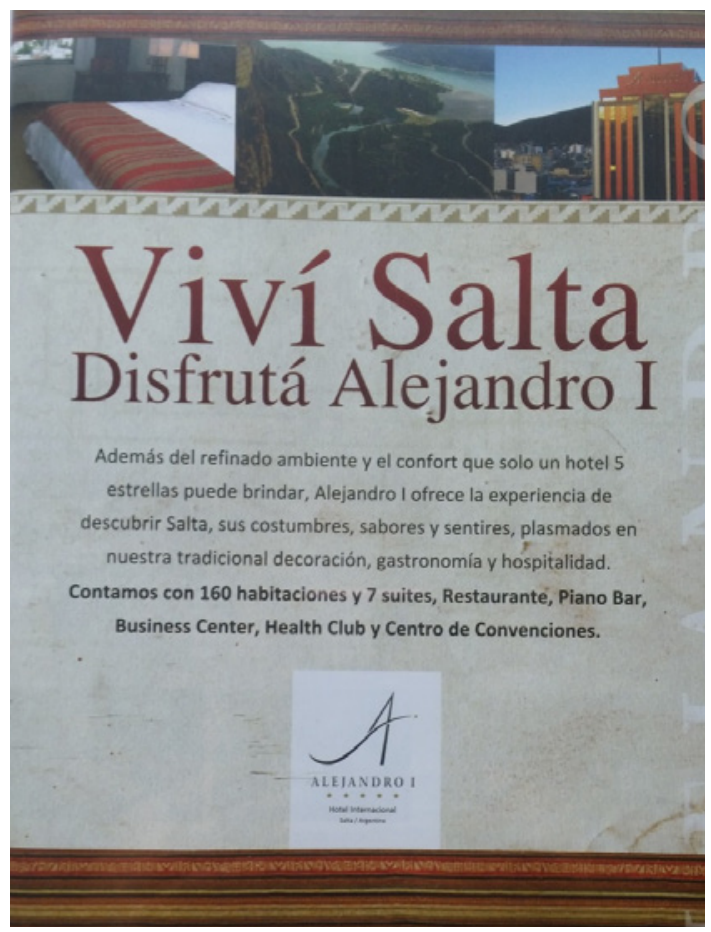

16 "Una nueva propuesta en la hotelería salteña, con lo mejor de lo nuevo y lo más puro de lo tradicional de esta tierra de encantos, colores y sabores. Un establecimiento pensado con el concepto de brindarles una opción de alojamiento con el espíritu arquitectónico salteño y con un alto grado de calidad, confort y calidez" (Posada del Marqués, 2016). 
Por otro lado, también ha cobrado peso la promoción y organización de Salta como un destino de turismo de reuniones. Aquí juega un rol central la inauguración en 2007 del centro de convenciones que se erigió a partir del préstamo otorgado por el BID para el fomento del turismo. Él se presenta como un exponente de la modernidad y la tecnología que puede ofrecer la ciudad en materia de turismo y además como un elemento que nuevamente es presentado destacando a Salta en el contexto nacional ${ }^{17}$. A esto se le suma la posibilidad que brindan otros espacios de la cuidad (Casa de la Cultura, Centro Cultural América, Teatro Provincial, Club 20 de Febrero) y los hoteles, muchos de ellos inaugurados en los últimos 15 años $^{18}$. La hotelería salteña, además de ofrecer la posibilidad de ser sede de reuniones, favorece la concreción de este tipo de eventos a partir de la cantidad de plazas que reúne.

La organización de eventos de todo tipo ha sido uno de los puntos destacados en los intentos por dar visibilidad a las ciudades competitivas. En el caso de Salta, y como parte de la política pública provincial recientemente se ha estimulado una oferta de eventos culturales entre los que se destacan diversos conciertos de figuras destacadas que no solían realizar presentaciones en esta (u otra) ciudad del noroeste (más bien su presencia quedaba circunscripta a las ciudades más grandes del país) ${ }^{19}$. En referencia a los conciertos una publicación vinculada al turismo de eventos en Salta (editada por una empresa cercana al poder político provincial) afirma que Salta "tiene un lugar en el circuito, que antes solo incluía a ciudades como Buenos Aires y Córdoba" (Revista Sede Salta, 2011), marcando el lugar que se busca que ocupe Salta en el contexto nacional. Además de estos eventos culturales también se desarrollaron otros de índole deportiva vinculados al fútbol y al rugby ${ }^{20}$ a los que se suman las últimas ediciones del Rally Dakar realizadas en Sudamérica desde 200921.

Otro de los aspectos de la ciudad que sirvió para mostrarla como un lugar vanguardista vino de la mano de presentar y organizarla como "ciudad del diseño". La idea de una ciudad que ofrece objetos de diseño se plasma en un conjunto de locales orientados a la comercialización de todo tipo de objetos de diseño "de autor" (indumentaria, decoración y bazar, muebles, etc.) muchos de los cuales resignifican lo "norteño" en productos de cierta exclusividad (ver figura 4). Estos locales comerciales se ubican en el centro histórico de la ciudad, en la zona comercial que comparten con otros locales de ventas de artesanías y productos regionales más tradicionales y otros rubros como agencias de viaje, gastronomía,

17 "Salta cuenta con una interesante oferta cualitativa y cuantitativa de sedes y prestadores, y con el Centro de Convenciones más moderno del país, con tecnología de última generación y con capacidad para 2400 personas" (Ministerio de Cultura y Turismo de Salta, 2012b, p. 60).

18 Según la publicación Turismo de reuniones. Congresos y convenciones que elaboró el Ministerio de Cultura y Turismo existen 21 establecimientos hoteleros que brindan espacios para reuniones en distintos lugares de la provincia (ciudad de Salta, San Lorenzo, Cafayate, Cabra Corral, Cachi y Rosario de la Frontera). Dieciséis se localizan en la ciudad de Salta; 10 de ellos forman parte de los establecimientos hoteleros surgidos en el centro histórico de la ciudad en los últimos 15 años con el boom del turismo (Ministerio de Cultura y Turismo de Salta, 2013b).

19 Entre los eventos musicales que se desarrollaron en la ciudad se destacan los conciertos de Shakira (2011), Joaquín Sabina y Joan Manuel Serrat (2012) y Ricardo Arjona (2014).

20 Estos eventos incluyeron partidos por torneos nacionales e internacionales en los que participaron las selecciones nacionales de ambos deportes (entre ellos se destaca la Copa América 2011).

21 Varias de ellas han pasado por distintos lugares de la provincia de Salta y su capital provincial siempre se ha constituido en un punto central para alojar a los interesados en el espectáculo. 
etc. La idea de reforzar esta asociación de Salta con el diseño se forjó en el marco de un evento organizado en 2010 denominado "Semana del diseño en Salta" del cual participaron la Fundación Pro Tejer, el Observatorio de Tendencias del Instituto Nacional de Tecnología Industrial (Textiles) y la Municipalidad de Salta. Estuvo orientado a "apoyar y difundir el trabajo de los emprendedores de diseño de indumentaria, accesorio, calzado y joyería de autor", según afirma el folleto que promocionaba el evento. Además se creó el recorrido "Por la calle, circuitos de diseño" que reunía un conjunto de locales con este tipo de oferta que ya existía en la ciudad. En años posteriores se reeditó ese evento y quedó consolidada lo que hoy el Ministerio de Cultura y Turismo de la provincia bautizó como la Ruta del Diseño, un recorrido que en capital provincial reúne más de 15 locales concentrados principalmente en las calles Buenos Aires y Caseros. La presencia del diseño en la ciudad de Salta no se limita a artesanías, indumentaria, muebles y objetos varios. La tradicional gastronomía local también ha sido redefinida con nuevas propuestas novedosas de la mano de las nuevas tendencias de cocina gourmet. Ingredientes y preparaciones asociadas fuertemente a la producción agropecuaria y la gastronomía del noroeste del país sirven de punto de partida para propuestas renovadas y refinadas en lo que se ha denominado "cocina de altura". Esto forma parte de una tendencia que se hace presente en todo el noroeste y que responde a nuevas propuestas de servicios especializados, sofisticados y novedosos para un turista conocedor y cosmopolita ("propuestas distinguidas y con características norteñas"22) ofrecidos en locales también acondicionados con una ambientación vanguardista y exclusiva. Esto, por supuesto, se combina con la oferta enológica que ofrece la provincia. Instituciones vinculadas al diseño y chefs especializados en la gastronomía local refrendan así un conjunto de productos y servicios que se pretenden distintivos.

Asimismo, la organización y puesta en funcionamiento del Museo de Arqueología de Alta Montaña (MAAM), inaugurado en 2004, ha constituido otro aspecto clave de la renovación de los atractivos de la ciudad ${ }^{23}$, pero especialmente condensa como ningún otro esta asociación entre pasado/patrimonio y cosmopolitismo/vanguardia que exhiben las ciudades competitivas. En torno a este proyecto creado para "albergar, preservar difundir el importante hallazgo arqueológico hallado en 1999 en el volcán de Llullaillaco, Salta, Argentina" (MAAM, 2012: 1) se combinan varios elementos que lo hacen uno de los principales puntos de la ciudad que despierta interés turístico. En primer lugar, remite directamente a un evento científico de relevancia internacional constituido por el hallazgo de tres cuerpos de más de 500 años de antigüedad encontrados en ese volcán en un estado de conservación poco frecuente. El hallazgo fue producto de una expedición científica realizada en 1999 al volcán de Llullaillaico (en la zona de puna de la provincia de Salta), financiada por la National Geographic Society ${ }^{24}$. Como parte de las excavaciones en la cima del volcán se desenterraron los cuerpos de tres niños con diversos objetos. Los detalles de la expedición forman parte de la información que el museo ofrece a los visitantes a través de audiovisua-

22 Según la presentación del restaurante de uno de los hoteles que además se promociona como un propuesta que conjuga "sofisticación y diseño" (Revista Sede Salta, 2010).

23 Este museo reconocido mundialmente concentra casi el $50 \%$ de las visitas a todos los museos de la provincia.

24 La expedición estuvo liderada por Johan Reinhard quien fue acompañado de montañistas y arqueólogos peruanos y argentinos. 
les donde se pone de relieve la relevancia del hallazgo. En segundo lugar, a partir de este evento se generó un atractivo de primer orden y carácter excepcional como son los cuerpos que lograron ser preservados y exhibidos en el museo. Al momento de presentarlos en los materiales de difusión suele ponerse de relieve su alto grado de conservación y también el hecho de que (junto con los otros objetos hallados) dan a conocer aspectos de las sociedades prehispánicas que habitaron esa parte del continente americano. En tercer lugar, el proyecto exhibe los aspectos referidos a la tecnología de punta empleada para investigar, conservar y exhibir los cuerpos (ver figura 5). Y por último, el mismo museo se constituye en un ejemplo de organización y diseño museístico de vanguardia, muy novedoso en el contexto regional ${ }^{25}$. Aquí se destacan la presentación de las colecciones en vitrinas diseñadas con tecnología que controla las condiciones del entorno de estos objetos y los soportes tecnológicos que permiten la proyección de los materiales audiovisuales. A esto hay que sumarle el hecho de que el museo funciona en uno de los edificios emblemáticos del proceso de renovación del centro histórico de la ciudad ${ }^{26}$. Proezas y hallazgos científicos, instituciones internacionales prestigiosas, tecnología de punta y soluciones científicas innovadoras se conjugan con un legado prehispánico de carácter extraordinario todo ello cobijado, explicado y exhibido en un edificio que conjuga él también lo histórico y lo nuevo. Desde la promoción oficial esto se presenta como un atractivo de primer nivel.

\section{Figura 4 \\ FOLLETO DE PROMOCIÓN DE PRODUCTOS DE DISEÑO (2011)}

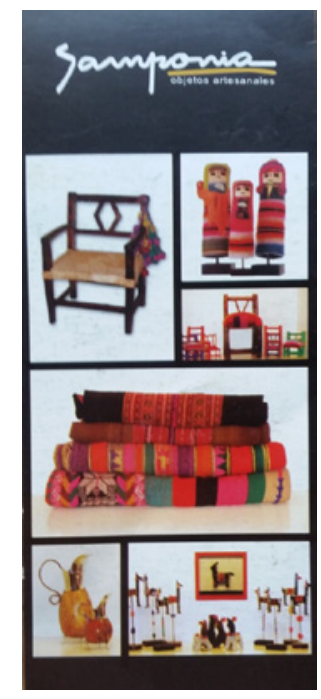

25 En el ámbito provincial otro proyecto posterior acompaña al MAAM como museo de vanguardia; se trata del Museo de la Vid y el Vino ubicado en la localidad de Cafayate e inaugurado en 2011 que también está inspirado en novedosas formas de organización museística, en este caso en torno a la temática del vino.

26 Se trata de un edificio de mediados del siglo XIX de estilo neogótico que en sus inicios una residencia familiar y luego sede de dependencias públicas, entre ellas, el Consejo General de Educación. Se ubica en la esquina de Mitre y España (frente a la plaza principal 9 de Julio). 


\section{Figura 5 GUÍA DEL MUSEO DE ARQUEOLOGÍA DE ALTA MONTAÑA (2012)}

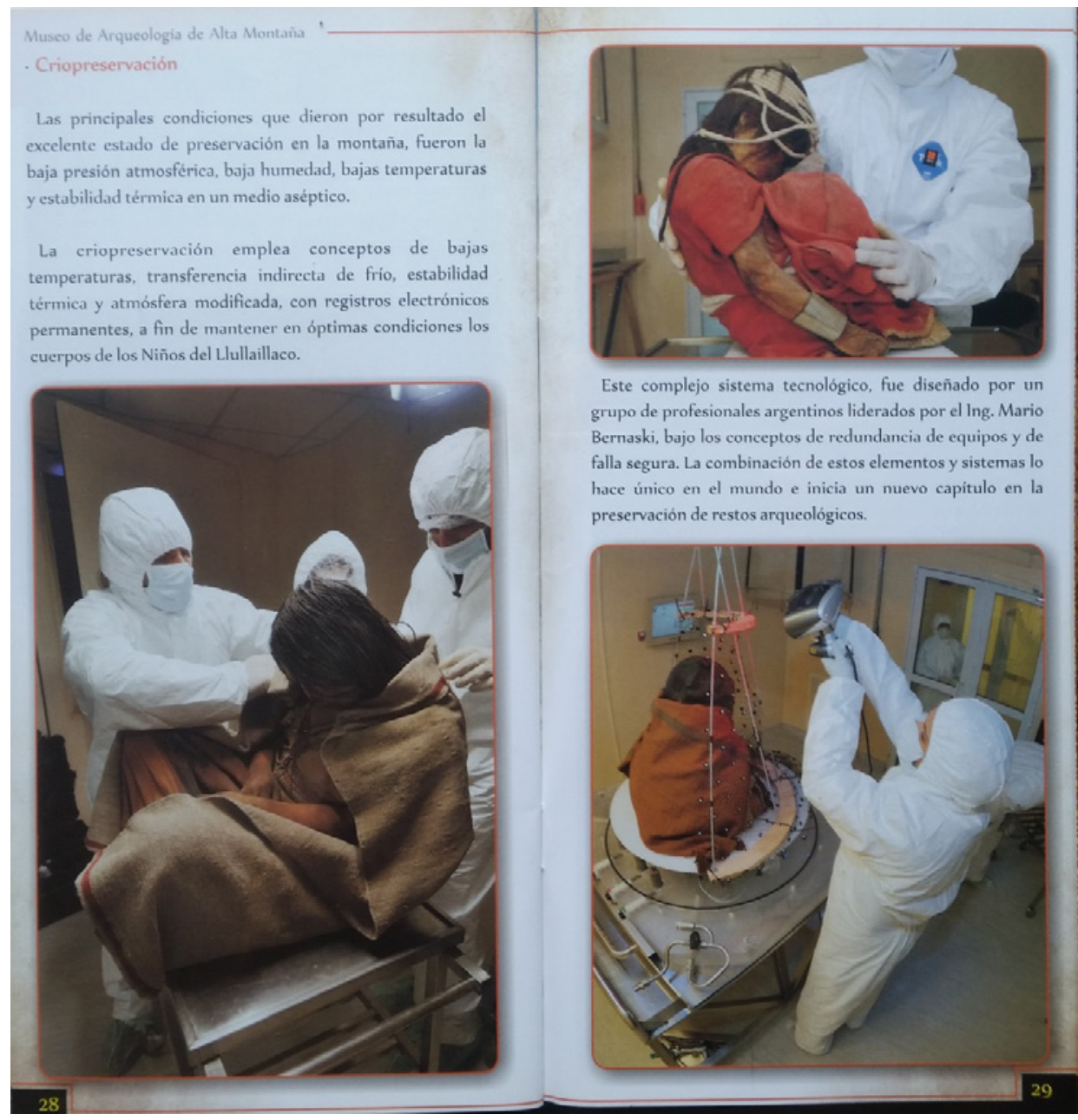

El carácter cosmopolita de la ciudad, por último, se lo da la presencia de los propios turistas, especialmente los internacionales, que en las últimas décadas se hacen presentes con mayor frecuencia que antaño en varios destinos del país, incluida esta ciudad del noroeste. Así lo expresa el gobernador en el texto que inaugura una publicación oficial de turismo: "Es normal que al entrar en cualquier lugar de Salta, se escuchen voces en francés, inglés, alemán y los más variados acentos latinoamericanos. El mundo ha descubierto a Salta y nosotros, quienes nacimos y vivimos en ella, somos felices por esto" (texto firmado por el gobernador Juan Manuel Urtubey al inicio del libro Salta, tan linda que enamora; Ministerio de Cultura y Turismo, 2012b). De esta forma los turistas son en 
gran medida destinatarios de toda la promoción que se realiza de la ciudad como destino turístico destacado pero, a su vez, también son presentados ellos mismos como atractivos o elementos distintivos de esta ciudad. Ellos son evidencia del carácter cosmopolita de Salta y de que esta ciudad "es el lugar donde se debe estar" (Urry y Larsen, 2011: 226).

Este perfil de turista parece coincidir con la descripción que realiza Cohen (2005: 16) del post-turista que busca "satisfacer gustos diferentes, a menudo sofisticados y lograr una distinción social al demostrar la posesión de capital cultural" en la búsqueda de experiencias distintivas. Pero estas experiencias, a su vez, están teñidas de cierta familiaridad. Busca lo novedoso pero en el marco más amplio de una cultura contemporánea de extensión global que le es familiar. Así, estos lugares de los que disfruta ofrecen ciertos elementos de familiaridad y seguridad (Ritzer y Liska, 2002): servicios, ambientaciones, productos que pueden ser encontrados en sus lugares de residencia (tal vez también ciudades cosmopolitas). De alguna manera, como propone Cohen (2005), para este turista la práctica de viaje es una extensión de sus prácticas habituales de ocio. Y en Salta, como en otros lugares visitados, es aquello que puede contribuir también a definir o reforzar la propia identidad cosmopolita de los turistas (Hiernaux, 2011).

Todos estos aspectos hablan de una localidad que apunta al turismo haciendo valer su condición de ciudad moderna además de ciudad patrimonial. Existen claros intentos por presentar a la ciudad con "todo lo que tiene que tener" para atraer a un turista cosmopolita e internacional. Consumo, ocio, diversión, entretenimiento y descanso parecen ser las claves en las cuales se disfruta y se definen los usos del centro histórico de Salta, presentada como una ciudad tradicional, pero también vanguardista y sofisticada. En definitiva, desde el sector público y el sector privado se ha procurado que Salta ofrezca estas nuevas formas de inversión en capital cultural que caracterizan a aquellas ciudades post-industriales que han buscado destacarse (Ward, 2005; Zukin, 1995). Pero también (y entre otras cosas, por eso mismo) Salta se perfila como el lugar para disfrutar de un estilo de vida particular como habitante de la ciudad.

\section{TURISTAS, RESIDENTES Y ESPACIOS DE CONSUMO EN EL CENTRO HISTÓRICO}

El carácter renovado que se ha buscado imprimir a la ciudad en los últimos años, basado en el destaque del pasado local y los aires cosmopolitas, ha sido atractivo no solo a visitantes sino también a los mismos habitantes de la ciudad. Como parte de los procesos recientes de transformación del centro histórico se ha producido una dinamización del mercado inmobiliario que no se orientó exclusivamente al turismo ${ }^{27}$. La construcción de edificaciones para vivienda, junto con la instalación de nuevos locales comerciales, han sido otros usos que se sumaron al turístico, a pesar de las críticas que despertaron estas transformaciones en el centro histórico ${ }^{28}$. Actores vinculados al mercado inmobiliario argumentaban que "es inevitable que una ciudad cosmopolita crezca, nos guste o no. Tiene que haber alternativas que

27 Entrevistas personales con miembros de la Cámara de Turismo y del Ministerio de Cultura y Turismo de la provincia, junio de 2011 y septiembre de 2012.

28 El crecimiento en altura de la edificación en el centro histórico se objetó porque este proceso, en algunos casos, venía de la mano de la demolición de edificios históricos; en otros casos, se señaló que la densificación de 
contemplen este crecimiento"29 y este crecimiento se efectivizó en un contexto donde aún no se encontraba definida una normativa patrimonial para el centro histórico.

Estas iniciativas apuntaron a brindar nuevas opciones residenciales a un sector de clase media o media alta local que no solo se beneficiaria de gozar de una ubicación céntrica sino también de un área que se renovaba en sus posibilidades de consumo. Estos sectores privilegiados de la sociedad local habían abandonado el centro de la ciudad como ámbito de consumo y recreación y se habían refugiado en el centro comercial creado durante los '90 (localizado a unas diez cuadras de la plaza principal). La década de 2000 los trae de vuelta de la mano de la dinamización del mercado inmobiliario, así como también atrae actores interesados en bienes inmuebles como una forma de inversión (Hendler, 2007) 30 . En esta área de la ciudad pueden encontrar un centro histórico como los de tantas otras ciudades que apostando por su patrimonio edificado buscaron potenciarlo asociándolo con múltiples opciones de consumo para un turista y un residente cosmopolita.

\section{Figura 6 \\ UNO DE LOS LOCALES GASTRONÓMICOS EN EL ÁREA DE “PALERMITO”}

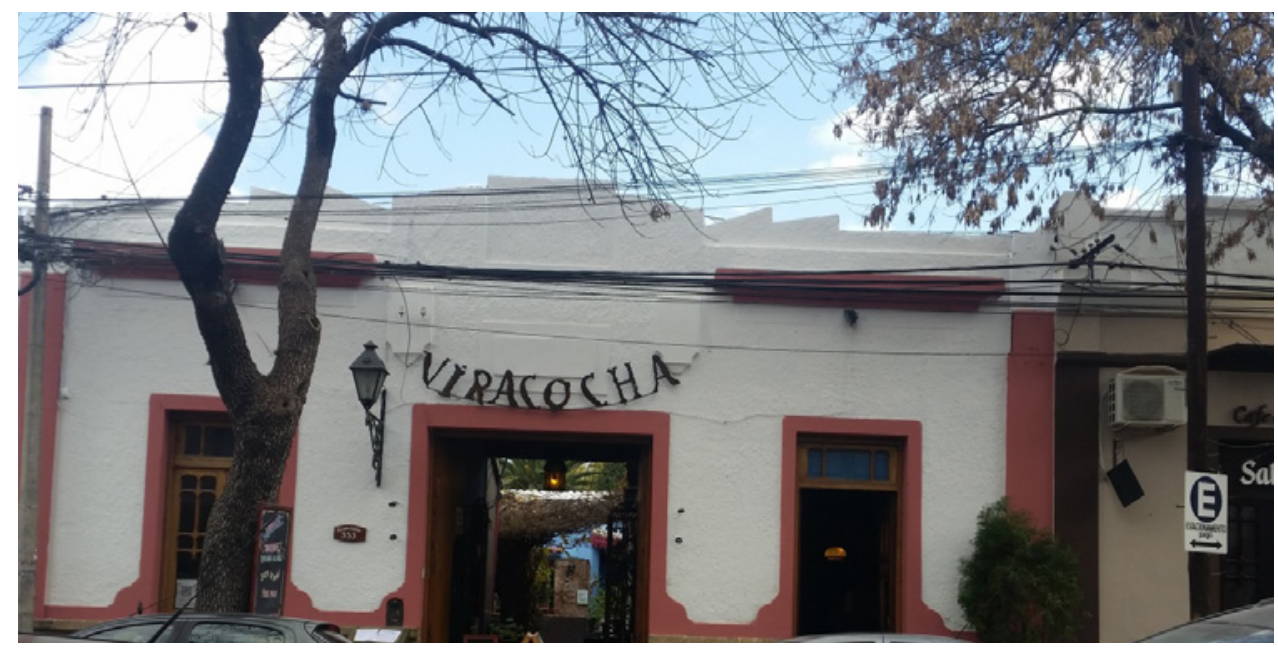

Los nuevos residentes, junto con los turistas (con quienes comparten preferencias de consumo; Zukin, 1995, Herzer, 2008), disfrutan de estos nuevos espacios de ocio en un entorno patrimonial renovado: tal como lo manifestaron en entrevistas personales empresa-

esta área de la ciudad haría peligrar el acceso a los servicios básicos (entrevista personal con responsable de la organización Red Sol que llevó adelante denuncias sobre este tema; septiembre de 2012).

29 En palabras de un empresario inmobiliario de la ciudad (El Tribuno, 2011).

30 Pero la llegada de población con mayores recursos no fue exclusiva del centro histórico. Estos sectores también han participado desde la década de 1990 del crecimiento de las urbanizaciones cerradas en los alrededores de la capital provincial y de ocupación de municipios vecinos (Aguilar y Sbrocco, 2009). 
rios vinculados a diversos rubros ${ }^{31}$, ambos grupos frecuentan locales gastronómicos y locales de diseño, así como también espacios destinados al entretenimiento. En cierta medida, ambos están interesados en un lugar que sigue la tendencia de las grandes ciudades que cuentan con espacios acondicionados especialmente para ciertas formas de consumo marcados por la presencia de bares, locales de artículos de diseño, gastronomía novedosa y gourmet, etc.; en definitiva, espacios marcados por cierta convivialidad practicada en el espacio público. En la ciudad de Salta esto se expresa en los cambios recientes operados en una zona del centro conocida como "Palermito" en clara alusión al barrio Palermo de Buenos Aires, caso emblemático de transformación urbana marcada por estas tendencias (ver figura 6).

Así, turistas y residentes comparten el gusto por este centro histórico que procura recobrar cierta condición urbanita perdida (Hiernaux, 2015), y que, además, suma otros elementos de interés frecuentemente asociados a un estilo de vida propio de las ciudades actuales como son la fuerte apuesta por la seguridad, la ausencia de venta ambulante y el cuidado del ambiente ${ }^{32}$.

Estos son los aspectos de la ciudad que se muestran desde la gestión local, que aprecian los turistas y sobre los que insiste el sector privado vinculado al turismo. Se promocionan formas de visitar y vivir la ciudad que combinan aquellos aspectos "positivos" 33 admirados en otras ciudades como, por ejemplo, su vida cultural y sus opciones para el consumo pero mostrando un esfuerzo por no copiar lo que consideran sus aspectos negativos. Así lo expresa la gerente de un hotel 4 estrellas de la ciudad: "Uno camina otras ciudades del país y dice: guau, ¡qué sucia que está!, ¡qué fea!, ¡qué abandonada! Y uno viene a Salta y dice: jestá hermoso! Bien cuidada, limpia, mantenida" (entrevista personal, junio 2011). Y claramente este contraste con otras ciudades funciona como un atractivo turístico de la ciudad ${ }^{34}$.

Los sectores privilegiados no son los únicos que disfrutan del centro; distintos sectores de la sociedad local se congregan en la plaza principal en determinados momentos del día (por ejemplo, comienzo y finalización del horario laboral y escolar) y de la semana (los fines de semana, especialmente al anochecer, suelen reunir a paseantes locales que recorren las peatonales y la plaza). Pero las transformaciones que tuvieron lugar en el centro histórico, especialmente en los aspectos vinculados al consumo, claramente se orientan a

31 Entre otros, propietarios de locales de objetos de diseño, gerentes de un restaurante, empresarios hoteleros y representantes de la Cámara de Turismo. Esto es también ampliamente reconocido por los funcionarios del Ministerio de Cultura y Turismo.

32 Como en tantos otros casos aquí también existen intentos por hacer de Salta una "ciudad verde". Bajo el nombre de "Revolución Verde" desde el municipio se inició en 2014 una campaña medioambiental que incluye aspectos como manejo de residuos, forestación, uso racional y eficiente de la energía y capacitaciones en el tema.

33 La difusión oficial en redes sociales de un artículo de febrero de 2015 de la BBC que menciona a Salta entre las mejores ciudades para vivir (BBC Mundo, 2015) volvió a reforzar la imagen positiva de la ciudad que históricamente se construyó sobre slogans como "Salta la linda" y otros más recientes como "Salta tan linda que enamora".

34 La seguridad (tema que interesa a algunos turistas que provienen de grandes ciudades) aparece presentada como una virtud más de la ciudad: "Salta es una ciudad segura y tranquila, no obstante todo el centro de la Ciudad y el Corredor Turístico de Calle Balcarce poseen cámaras de seguridad en vigilancia permanente y policías uniformados recorriendo las calles las 24 hs." (sitio web de la Secretaría de Turismo y Cultura de ciudad de Salta). También desde el sector empresarial turístico el presidente de la Cámara de Turismo afirma que "Salta es la ciudad más segura del país" (QuepasaSalta.com.ar, 2013). 
consumidores específicos, con gustos compartidos, que comprenden tanto a los turistas como a los sectores de la sociedad local con mayores recursos. Como señaláramos en otro lugar (Troncoso, 2012) existen algunos usos del centro histórico que son vetados, como la venta ambulante ${ }^{35}$. No todos tienen acceso a esta área de la ciudad y como señalan Young, Diep y Drabble, (2006) la aceptación de la diferencia que parece ser una característica central en estas ciudades con aires cosmopolitas funciona en algunos sentidos y no en otros.

Cabe aclarar que, como sucede en otras ciudades, los usos compartidos entre turistas y locales se limitan a ciertas áreas. En el caso de Salta este espacio lo constituye su centro histórico sujeto en los últimos años a un proceso de intervención público-privada para hacer de esta área de la ciudad un espacio destacado. Los turistas, en general, no se aventuran más allá de estas áreas renovadas excepto para visitar las localidades cercanas a la ciudad capital como San Lorenzo, La Caldera, etc., o para realizar las excursiones hacia otros destinos de la provincia o la región. Por fuera de las áreas más destacadas de la ciudad otras son las problemáticas sociales como, por ejemplo, la desocupación, los problemas de acceso a la vivienda, la ocupación de tierras, las carencias del sistema de transporte (que se extienden al área patrimonial), los problemas de disposición de residuos y la carencia de acceso a la provisión de servicios públicos ${ }^{36}$. Salta no parecería ser la excepción para las propuestas que interpretan los procesos de renovación urbana como procesos de diferenciación social y espacial (Herzer, 2008).

\section{DISCUSIÓN Y CONCLUSIONES. ENTRE EL PATRIMONIO Y LA VAN- GUARDIA: LA CREACIÓN DE UNA CIUDAD TURÍSTICA "COMPETITIVA"}

En la provincia de Salta, en los últimos años, se ha hecho evidente el interés por apostar al turismo como una actividad de relevancia. En este proceso la ciudad capital constituye un punto central por ser centro de llegada y distribución de turistas pero también por los propios atractivos de este centro urbano. Entre ellos el patrimonio (edificado e histórico, principalmente) ha jugado un rol central. Pero además de estos aspectos se ha buscado mostrar y transformar a Salta en un centro urbano moderno, que comparte algunos rasgos con otros centros destacados a nivel nacional e internacional: el rescate de la ciudad tradicional se articula con los intentos por definir una ciudad inserta en el mundo actual. La mirada nostálgica hacia el pasado de esplendor se combina con una mirada a un futuro promisorio; la "postal obligada" se encuentra con la necesidad de atender a las demandas del turista postmoderno (Amirou, Pauget, Lenglet y Dammak, 2011). Y en este proceso se busca establecer una diferencia entre este destino y otros del noroeste, exclusivamente asociados con lo patrimonial, lo tradicional, lo vernáculo (en término de sus atractivos culturales). Esta idea, desplegada a nivel discursivo hace hincapié en que ahora Salta tam-

35 Y en parte esto es instrumentado por la misma normativa que rige para el área patrimonial. La presencia de los vendedores ambulantes ha sido restringida a lugares específicos (alejados de la plaza principal) y momentos particulares del día (por la noche o en horario de la siesta). No obstante, la venta ambulante no se encuentra totalmente anulada.

36 Algunos datos sobre estas cuestiones pueden encontrarse en Centro de Estudios para el Desarrollo Humano y la Prosperidad- ODSA- UCA (2014). Para el tema de acceso a la vivienda y conformación de asentamientos, véase Aguilar y Sbrocco (2009). 
bién aparece como sede de procesos y eventos que son propios solo de algunas grandes ciudades en el contexto nacional.

El incremento del capital simbólico implicado en este proceso se vincula a varias de las estrategias y temáticas que han transformado otros centros urbanos presentados como modelo a seguir: se colocó en destaque su patrimonio renovado; se organizaron eventos distintivos; se le dio un lugar a la creatividad, el diseño y la nueva gastronomía que recupera lo vernáculo; se apostó a la creación de un museo de relevancia internacional; se invirtió en infraestructura y equipamiento y se crearon las bases para la concreción de una serie de servicios orientados a un turista consumidor con exigencias especiales.

Estas transformaciones operadas en la ciudad implicaron la actuación de actores clave. Por un lado, el poder político (a niveles provincial y municipal) forjó esta imagen de la ciudad, a la vez que estableció las bases para la realización de inversiones desde el sector privado. Esto incluyó tanto inversiones en infraestructura como gestión de recursos financieros y herramientas normativas. En efecto, los aspectos normativos también formaron parte importante del accionar del sector público buscando modelar el centro histórico para que responda a la imagen que de él se buscaba y ofreciendo ciertas facilidades para el desarrollo de emprendimientos, especialmente hoteleros. El sector privado, por su parte, aprovecha estas ventajas organizando propuestas que definen espacios de residencia y ocio orientados fundamentalmente a turistas y a ciertos sectores de la sociedad local. Así, el poder político con sus tareas de promoción turística, protección patrimonial, desarrollo de infraestructura y beneficios para inversiones allana el camino para el trabajo del sector privado que consolida su presencia en la ciudad revitalizando, a su vez, el comercio y los servicios. Por último, el saber experto (científico, cultural, artístico) y sus instituciones de renombre otorgaron un conocimiento específico, asesoramiento técnico y trabajo profesional que sirvieron para prestigiar, legitimar y fijar en normativas las formas en que se transformó el espacio público en el centro histórico. Asimismo, avalaron el carácter distintivo, único o excepcional de algunos de los bienes y servicios que se ofrecen y consumen en esta área de la ciudad.

En gran medida las intervenciones al centro histórico parecen estar orientadas por lo que Hiernaux (2006) llama imaginario patrimonialista, el cual no solo guía estas intervenciones como una simple tematización vinculada al pasado sino que está fuertemente asociada a la definición en el presente de cierta identidad, la salteña, marcada por su grandeza y su relevancia en la historia regional y nacional. Pero las ideas asociadas a cierto esplendor no quedan solo en el pasado, sino también en el presente. Con este perfil vanguardista, cosmopolita e innovador (apoyado en un conjunto de ideas y acciones que transforman la ciudad) ella se distingue de sus vecinas en una proyección nacional reclamada como exclusiva.

Asimismo, este proceso de transformación vinculado al turismo estará marcado por la (re)creación de diferencias, de una multiplicación de las opciones (de especificidades geográficas) que se suman a otros atractivos y formas de aprovechamiento turístico más asentadas. El centro histórico, así, se renueva constantemente modificando las temáticas que inspiran su transformación. Esto implica nuevas opciones para los consumidores pero también para el sector privado que "explota" nuevos aspectos de la ciudad para crear nuevos productos, servicios y experiencias. 
Estos cambios acompañan tendencias generales de pensar e implementar la gestión de las ciudades actuales. La intervención turística atendiendo fundamentalmente a cuestiones estéticas caracteriza las nuevas tendencias en materia de planificación que han abandonado las miradas más holísticas y centradas en las necesidades de la sociedad local que caracterizaron a las propuestas de planificación moderna que predominaron en el siglo XX. Estas nuevas formas ponen el foco solo en algunas áreas de la ciudad (Harvey, 1989; Zukin, 1995; Young, Diep y Drabble, 2006): en el caso de Salta, la ciudad patrimonial, moderna, con sus edificios remozados y sus condiciones de limpieza y seguridad fue la que congregó nuevos consumidores (entre ellos turistas) que allí llevan adelante sus prácticas de consumo vinculadas al ocio y el entretenimiento.

El turismo participa de las transformaciones espaciales orientadas hacia nuevas formas de consumo que reformulan el espacio urbano, dando lugar también a diferenciaciones espaciales (Meethan, 2001). En relación con esto, las intervenciones que orientaron estas transformaciones se centraron en un área en particular marcada por cierta exclusividad que congrega a consumidores específicos. En efecto, el perfil de ciudad buscado estuvo orientado a cierto tipo de consumidores interesados en estos aspectos distintivos de la ciudad que hablan de una apreciación por lo histórico y patrimonial pero también por lo cosmopolita y vanguardista. En relación con esto, los usos de ocio definidos para el centro histórico parecerían invitar parcialmente a otros habitantes (y también visitantes -los turistas de menores ingresos-) a compartir este espacio embellecido, saneado y controlado. En relación con esto es que cobra sentido la pregunta acerca de cómo participa el turismo en la creación de diferenciaciones en el espacio urbano de la ciudad (que siempre existieron) ahora acentuadas y profundizadas. También toma relevancia la pregunta acerca de cómo el turismo justifica estas transformaciones y diferenciaciones con sus argumentos clásicos acerca de desarrollo y de derrame que siempre están "al llegar" allende las fronteras de los ámbitos concretos de intervención (sociales, geográficos).

Al mismo tiempo, este proceso de transformación de la ciudad (que tiene al turismo en su núcleo) se transforma en la cara visible, "exitosa" y renovada de un proyecto político que busca destacar Salta "la linda" (y no otra) en el contexto regional, nacional y también internacional. Aquí la condición de vidriera turística definida por estos procesos no está exenta de implicancias y utilizaciones políticas que exceden la mera promoción de un destino turístico. En ese sentido, podemos preguntarnos qué papel juegan estos cambios urbanos orientados a definir un perfil particular para la ciudad en ciertos proyectos políticos que buscan trascender el ámbito local.

\section{REFERENCIAS BIBLIOGRÁFICAS}

AGUILAR, M.Á. Y SBROCCO, M.E. (2009): «Transformaciones e improntas urbanas en un espacio local. El caso de Vaqueros, Salta», Cuaderno urbano, vol 8, n8, pp. 159-180.

ÁLVAREZ LEGUIZAMÓN, S. y VILLAGRÁN, A. (2010): «Artes de gobierno y estrategias de legitimidad en la etapa neoliberal en Salta, el gobierno de Juan Carlos Romero», en Poder y salteñidad: saberes, políticas y representaciones sociales. Salta, CEPIHA, pp. 215-251 
AMIROU, R., PAUGET, B., LENGLET, M. y DAMMAK, A. (2011): «De l>image à l>imagerie en passant par l>imaginaire: une interprétation du tourisme à partir des représentations proposées par dix villes européennes», Recherches en Sciences de Gestion, n 86, pp. 87-102.

BOYER, M.C. (2004): «Ciudades en venta: la comercialización de la historia en el South Street Seaport», en Variaciones sobre un parque temático. La nueva ciudad americana y el fin del espacio público. Barcelona, Gustavo Gili, pp. 205-230.

BRITTON, S. (1991): «Tourism, capital, and place: towards a critical geography of tourism», Environment and Planning, D Society and Space, $\mathrm{n}^{\circ}$ 9, pp. 451-478.

COHEN, E. (2005): «Principales tendencias en el turismo contemporáneo», Política y Sociedad, vol $42 \mathrm{n}^{\circ} 1$, pp. 11-24.

DUHAMEL, P. (2005): «Patrimoine et modernité: double logique de la production et du renouvellement des villes touristiques», en Mondes urbains du tourisme. Paris, Belin, pp. 297-307.

FEATHERSTONE, M. (2002): «Cosmopolis. An introduction», Theory, Culture \& Society, vol 19, $\mathrm{n}^{\circ} 1-2$, pp. 1-16.

HARVEY, D. (1989): «From managerialism to entrepreneurialism: the transformation in urban governance in late capitalism», Geografiska Annaler. Series B, Human Geography, vol 71, n¹, pp. 3-17.

HARVEY, D. (1998): La condición de la posmodernidad. Investigación sobre los orígenes del cambio cultural. Buenos Aires, Amorrortu.

HARVEY, D. (2002): «The art of rent: globalization, monopoly and the commodification of culture», Socialist Register 2002: A World of Contradictions. Disponible en https:// socialistregister.com/index.php/srv/article/view/5778/2674.

HERZER, H. (2008): «Acerca de la gentrificación», en Con el corazón mirando al sur: transformaciones en el sur de la Ciudad de Buenos Aires. Buenos Aires, Ed. Espacio, pp. 13-44.

HIERNAUX, D. (2006): «Los centros históricos: ¿espacios posmodernos? (De choques de imaginarios y otros conflictos) », en Lugares e imaginarios en la metrópolis. México, Anthropos, pp. 27-41.

HIERNAUX, D. (2011): «Identidades cosmopolitas en las sociedades posmodernas», en Seminario Diversidad y Multiculturalidad en las Grandes Ciudades ¿Identidades o Ciudadanías?, 27-28 de junio 2011.

HIERNAUX, D. (2015): «Fantasías, sueños e imaginarios del turismo contemporáneo», en Turismo, Sociedad y Territorio: una lectura crítica. Facultad de Ciencias Políticas y Sociales, Universidad Autónoma de Querétaro, pp.65-96.

JAYNE, M. (2006): Cities and consumption. Londres, Routledge.

MATA DE LÓPEZ, S. (1998): «El caso de Salta en el noroeste argentino en la segunda mitad del siglo XVIII», Andes n 9, pp. 143-169.

MEETHAN, K, (2001): Tourism in global society. Place, culture, consumption. Nueva York, Palgrave.

RITZER, G. y LISKA, A. (2002): «'Mcdisneyization' and 'post-tourism': complementary perspectives on contemporary tourism», en Touring cultures, Transformation of tourism and theory. Londres, Routledge, pp. 96-109. 
SÁNCHEZ, F. (2001): «A reinvenção das cidades na virada de século: agentes, estratégias e escalas de ação política», Revista de Sociologia Política, n²16, pp. 31-49.

SÁNCHEZ, F. (2010): A reinvenção da cidade para um mercado mundial. Chapecó, Argos.

TRONCOSO, C.A. (2011): «Política turística provincial, atractivos y transformaciones recientes en la ciudad de Salta», en X Congreso Argentino de Antropología Social, 29 de noviembre al 2 de diciembre de 2011, Buenos Aires, Argentina.

TRONCOSO, C.A. (2013a): «Política turística y patrimonial en la ciudad de Salta (Argentina): disonancias en la protección y usos del centro histórico», Estudios y Perspectivas en Turismo, vol 22, n 6, pp. 1002-1024.

TRONCOSO, C.A. (2013b): «Espacio patrimonial, espacio de deleite visual y consumo. Transformaciones patrimoniales recientes y turismo en la ciudad de Salta (Argentina)», Espaço e Geografia, vol 16, n² 2, pp. 641-674.

URRY, J. (1995): «The consumption of tourism», en Consuming places. Nueva York, Routledge, pp. 129-140.

URRY, J. (2000): « The Global Media and Cosmopolitanism», en Transnational America Conference, Bavarian American Academy, Munich. Disponible en: http://www.lancaster.ac.uk/fass/resources/sociology-online-papers/papers/urry-global-media.pdf.

URRY, J. y LARSEN, J. (2011): The tourist gaze 3.0. Londres, Sage Publications.

VAINER, C. (2000): «Pátria, Empresa e Mercadoria. Notas sobre a estratégia discursiva do Planejamento Estratégico Urbano», en A Cidade do Pensamento Único. Desmanchando consensos. Petrópolis, Ed. Vozes, pp.75-103.

WARD, S. (2005): Selling Places. The Marketing and Promotion of Towns and Cities 1850-2000. New York, Taylor \& Francis.

YOUNG, C., DIEP, M, y DRABBLE, S. (2006): «Living with Difference? The 'Cosmopolitan City' and Urban Reimaging in Manchester, UK», Urban Studies, vol 43, ${ }^{\circ}$ 10, pp. 1687-1714.

ZUKIN, S. (1995): The cultures of cities. Oxford, Blackwell.

ZUKIN, S. (1998): «Urban lifestyles: diversity and standardization in spaces of consumption», Urban Studies, ${ }^{\circ}$ 35, pp. 825-839.

\section{FUENTES}

Ámbito Financiero (2016): «Urtubey celebró los buenos resultados del turismo invernal en Salta», 29/07/2016. Disponible en: http://www.ambito.com/849067-urtubey-celebrolos-buenos-resultados-del-turismo-invernal-en-salta (Consulta: 13/09/2016).

BID (2003): Programa de Apoyo al Desarrollo Integrado del sector turismo de la provincia de Salta (AR-0292). Propuesta de préstamo.

CENTRO DE ESTUDIOS PARA EL DESARROLLO HUMANO Y LA PROSPERIDAD- ODSA- UCA (2014): Estado del desarrollo humano y social en el Gran Salta, Buenos Aires.

El Tribuno (2011): «La zona más cara de Salta», 21/05/2011. Disponible en: http://www. eltribuno.info/la-zona-mas-cara-salta-n26942 (Consulta: 11/02/2013). 
El Tribuno (2012): «Miguel Isa: 'Salta tiene que estar entre las grandes ciudades del mundo'», 31/12/2012. Disponible en: http://www.eltribuno.info/miguel-isa-salta-tieneque-estar-las-grandes-ciudades-del-mundo-n238424 (Consulta: 2/09/2015).

El Tribuno (2015): «El movimiento turístico de enero dejó números alentadores», 1/02/2015. Disponible en: http://www.eltribuno.info/el-movimiento-turistico-enero-dejo-numerosalentadores-n501727 (Consulta: 2/09/2015).

HENDLER, Ariel, «Salta: crecimiento con identidad», Reporte inmobiliario. Disponible en: http://www.reporteinmobiliario.com.ar/nuke/article1012-salta-crecimiento-conidentidad.html (Consulta: 12/03/2012).

Informate Salta (2011): «Salta, meca del turismo de alta gama», 19/01/2011. Disponible en: http://www.informatesalta.com.ar/noticia.asp?q=21869 (Consulta: 20/01/2011).

La Gaceta (2015): «Febrero. El turismo dejó buenas cifras durante los fines de semana en Salta», 21/02/2015. Disponible en: http://www.lagacetasalta.com.ar/nota/14183/ turismo/lagacetasalta.com.ar (Consulta: 13/09/2016).

MAAM (Museo Arqueológico de Alta Montaña) (2012): Guía. Versión en español.

MINISTERIO DE TURISMO Y CULTURA DE SALTA (2007): Plan Maestro de Viajes \& Turismo de Salta 2006-2016, Salta.

MINISTERIO DE CULTURA Y TURISMO DE SALTA (2010): spot publicitario. Disponible en: https:/www.youtube.com/watch?v=8cT0yLO6AVs. (Consulta: 20/12/2010).

MINISTERIO DE CULTURA Y TURISMO DE SALTA (2011): «Conferencias de expertos catalanes sobre patrimonio arquitectónico», 10/11/2011. Disponible en: http:// www.salta.gov.ar/prensa/noticias/conferencias-de-expertos-catalanes-sobre-patrimonio-arquitectonicos/13348 (Consulta: 13/11/2011).

MINISTERIO DE CULTURA Y TURISMO DE SALTA (2012a): Plan Estratégico de Turismo Salta Sí + (2010-2020), Salta.

MINISTERIO DE CULTURA Y TURISMO DE SALTA (2012b): Salta. Tan linda que enamora, Salta.

MINISTERIO DE CULTURA Y TURISMO DE SALTA (2013a): Spot publicitario. Disponible en: https://www.youtube.com/watch?v=lKk3bVA9VrM (Consulta: 13/12/2013).

MINISTERIO DE CULTURA Y TURISMO DE SALTA (2013b): Turismo de reuniones. Congresos y convenciones, Salta.

MINISTERIO DE CULTURA Y TURISMO DE SALTA (2014): «En el 2013 el turismo de reuniones creció un 28\%», 25/07/2014. Disponible en: http://turismo.salta.gov.ar/contenido/1336/en-el-2013-el-turismo-de-reuniones-crecio-un-28- (Consulta: 2/09/2014).

MINISTERIO DE CULTURA Y TURISMO DE SALTA (2015): «El turismo generó un impacto económico de $\$ 570$ millones en enero y febrero», 3/03/2015. Disponible en: http://turismo.salta.gov.ar/contenido/1607/el-turismo-genero-un-impacto-economicode-570-millones-en-enero-y-febrero (Consulta: 13/09/2016).

MINISTERIO DE CULTURA Y TURISMO (2017): Informe Estadístico. Turismo 2016, Salta.

MINISTERIO DE FINANZAS Y OBRAS PÚBLICAS DE SALTA (2011): Plan Regulador del Área Centro, Salta.

Posada del Marqués, sitio web http://www.posadadelmarques.com.ar/ (Consulta 13/09/2016). 
Pulso turístico (2014): «Salta en cifras de invierno», 4/08/2014. Disponible en: http:// www.pulsoturistico.com/mas_informacion.asp?id=6113\&titulo=Salta-en-cifras-deinverno. (Consulta: 4/09/2015).

QuePasaSalta (2013) «'Salta es la ciudad más segura del país' aseguró el Presidente de la Cámara de Turismo», 12/09/2013. Disponible en: http://www.quepasasalta.com.ar/ noticias/salta_26/salta-es-la-ciudad-mas-segura-del-pais-aseguro-el-presidente-de-lacamara-de-turismo_49859 (Consulta: 2/09/2014).

Revista Sede Salta (2010) año 2, n5.

Revista Sede Salta (2011) año 2, nº 
